\title{
A Modified Harmony Search Algorithm for the Optimum Design of Earth Walls Reinforced with Non-uniform Geosynthetic Layers
}

\author{
Mohammad Motalleb Nejad $^{1} \cdot$ Kalehiwot Nega Manahiloh $^{1}$
}

Received: 2 September 2015/Accepted: 26 October 2015/Published online: 26 November 2015

(C) Springer International Publishing Switzerland 2015

\begin{abstract}
Traditional design and construction of reinforced earth walls assumes uniform length and spacing of reinforcements. Even though the assumption simplifies the design and construction efforts, the inherently conservative approaches followed in picking the final values for the reinforcement length and spacing result in unnecessarily big construction costs. This paper presents an improved harmony search-based approach that can be adopted to optimize the design of Geosynthetic-reinforced earth walls. An existing improved harmony search algorithm is modified into a new harmony search algorithm by extending its capabilities to consider permutation-based operations for inter-dependent variables. The involved optimization procedures are discussed in a step-wise approach. This novel approach allows the consideration of non-uniform length and spacing for the reinforcement layers. As such, length of the Geosynthetic reinforcement and the spacing between adjacent Geosynthetic layers are taken as the design variables to be manipulated until the cost of construction is optimized. Static and dynamic loads are considered. the application of the proposed optimization technique is demonstrated on Geosynthetic-reinforced earth walls of height 5,7 and $9 \mathrm{~m}$. The extent of cost saving is assessed by comparing the results of this work and previous work. The previous work selected for comparison uses harmony search algorithm to optimize the design and construction of Earth Walls reinforced with uniform length- and spacingGeosynthetic layers. The IHS-based optimization resulted in Cost reduction of up to $11 \%$.
\end{abstract}

Mohammad Motalleb Nejad

mohmtlb@udel.edu

1 Civil and Environmental Engineering, University of Delaware, 301 DuPont Hall, Newark, DE 19711, USA
Keywords Geosynthetics - Reinforced earth walls . Metaheuristic - Improved harmony search algorithm $(I H S A) \cdot$ Optimization - Pitch adjustment rate $(P A R)$. Harmony consideration rate $(H C R)$

\section{Introduction}

Retaining walls are among the most extensively used structural elements in the construction industry [1]. In spite of their ubiquitousness, applicability of non-reinforced retaining walls is confined to lower heights [2]. To overcome this limitation and enhance the performance of walls at higher heights, different types of reinforcing material were introduced. The tension-resisting element (i.e. the reinforcement) in reinforced earth wall systems works as a unit with surrounding soil to augment its strength and sustainability. One group of such reinforcements consists of different types of Geosynthetics. Geosynthetic reinforcements are fabricated from polymeric material. In reinforced earth systems, the Geosynthetic element plays the combined pivotal roles of isolation, increased tensile resistance and improved drainage. Use of Geosynthetics as reinforcement provides additional strength against various failure mechanisms. This in turn allows increasing the reinforced-wall height without the need for external lateral support (e.g. heavy gravity walls constructed by substantial concrete material [3]). The decent endurance of the polymeric material against erosion has made it a better choice in reinforcing earth structures [4]. These overlapping benefits have made Geosynthetic-reinforced walls favorable and their design and implementation is expanding. Over the past five decades the production and use of polymer-based reinforcement has shown a sustained upsurge. Geosynthetic reinforced soil walls, compared to 
the classic rigid-walls, have superior flexibility which makes them better in withstanding natural disasters such as earthquakes and landslides [3].

In addition to aforementioned benefits, in Geosyntheticreinforced soil walls, the cost of the construction is significantly lower than other earth retaining systems [5]. Construction cost is one of the decisive factors in the execution of engineering projects. Koerner and Soong [6] compared the cost of construction for different types of retaining walls and showed that the cost of construction for Geosynthetic-reinforced soil walls is by far lower than its classic competitors.

In recent studies, harmony search algorithm (HSA) has been applied in various engineering optimization problems. River flood models [7, 8], optimal rainfall-runoff models [9], a design of water distribution networks [10], a simultaneous determination of aquifer parameters and zone structures [11] are some applications of $H S A$ in the Civil Engineering discipline. HSA has also been applied in scheduling problems [12], steel frame designs [13], reliability optimizations [14], optimal design of planar and space trusses and the optimal mass and conductivity design of a satellite heat pipe $[15,16]$. Other studies that make use of HSA include: transport energy modeling problem [17], selecting and scaling real ground motion records [18], a water-water energetic reactor core pattern enhancement [19], solving machining optimization problems [20], pressurized water reactor core optimization [21].

Compared to other metaheuristic methods HSA possesses unique features in that it: considers all the solution harmonies during new iterations; and utilizes stochastic random searches. These features enable HSA to, systematically, handle huge optimization problems with less mathematical requirements [22] and make it a preferable tool in optimization-related research.

Recently, different methods (i.e. Particle Swarm Optimization (PSO), Ant Colony etc.) have been combined with $H S A$ in pursuit of improved hybrid-algorithms [23, 24]. Several other studies have also tried to further improve the performance of $H S A$. Wang and lee [25] proposed a differential harmony search algorithm in solving non-convex economic load dispatch problems. An improved harmony search $(I H S)$ [22] and a global-best harmony search $(G H S)$ [26] algorithms have been implemented to enhance the searching power of the HSA.

Basudhar et al. [27] optimized Geosynthetic-reinforced walls using Sequential Unconstrained Minimization Technique (SUMT algorithm). Using HSA, and assuming the constant-length and number of Geosynthetic layers as design variables and construction cost as the objective function, Manahiloh et al. optimized the design of Geosynthetic-reinforced walls [1]. In both studies the length of reinforcement and the spacing between adjacent layers were set to be constant.

In this study the applicability of $I H S$ is discussed and its utilization is demonstrated by optimizing the design and construction of Geosynthetic-reinforced Earth Walls. The algorithm associated with IHS is modified and expanded to account for non-uniform length of Geosynthetic reinforcement layers and non-constant spacing between adjacent layers. The optimization variables are: the independent lengths of Geosynthetic in each layer; and a vector that contains distance information between two adjacent Geosynthetic layers.

\section{Analysis of Geosynthetic-Reinforced Earth Wall}

Stability analysis for Geosynthetic-reinforced walls introduced in FHWA code [28] uses Rankine's theory. The same theory is adopted in this study to analyze walls while non-uniform variation in spacing and length of geosynthetic reinforcement is permitted. The non-uniform length and spacing values are set to be picked with a random selection process pre-defined in the HSA. The feasibility of construction is accounted for by constraining the variation in length of geosynthetics in such a way that it shows a consistent trend. Moreover, the length of geosynthetics in each layer is kept lower than the smaller of: the maximum limit of the range for length; and the length of geosynthetic in the layer above. Stability analyses, for Geosyntheticreinforced walls with a vertical face, are made assuming a rigid body behavior for the reinforced zone as shown in Fig. 1. Lateral earth pressures are computed on a vertical surface located at the end of the reinforced zone. The reinforced zone is further divided into multiple sub-zones. The first zone related to shortest length of the reinforcement which is associated with the bottom layer of Geosynthetics. The other zones are fractions of an assumed rigid body that exceed the area corresponding to the least length. Parameters used in the design process are presented in Fig. 1.

For horizontal and inclined backfill (angle $\beta$ from horizontal) retained by a smooth veritcal wall, the coefficient of active lateral earth pressure may be calculated from Eqs. (1) and (2) respectively.

$K_{\mathrm{a}}=\tan ^{2}\left(45-\frac{\phi}{2}\right)$

$K_{\mathrm{a}}=\cos \beta \times \frac{\cos \beta-\sqrt{\cos ^{2} \beta-\cos ^{2} \phi}}{\cos \beta+\sqrt{\cos ^{2} \beta-\cos ^{2} \phi}}$

In this study the active earth pressure coefficient $\left(K_{\mathrm{a}}\right)$ for the backfill is designated with $K_{\mathrm{ae}} \phi$ is defined as $\phi_{\mathrm{b}}$ and $\phi_{\mathrm{f}}$, for the soil in reinforced zone and the retained soil (i.e. 
Fig. 1 Parameters used in different steps of the design and external forces considered for the Geosynthetic reinforced retaining wall system
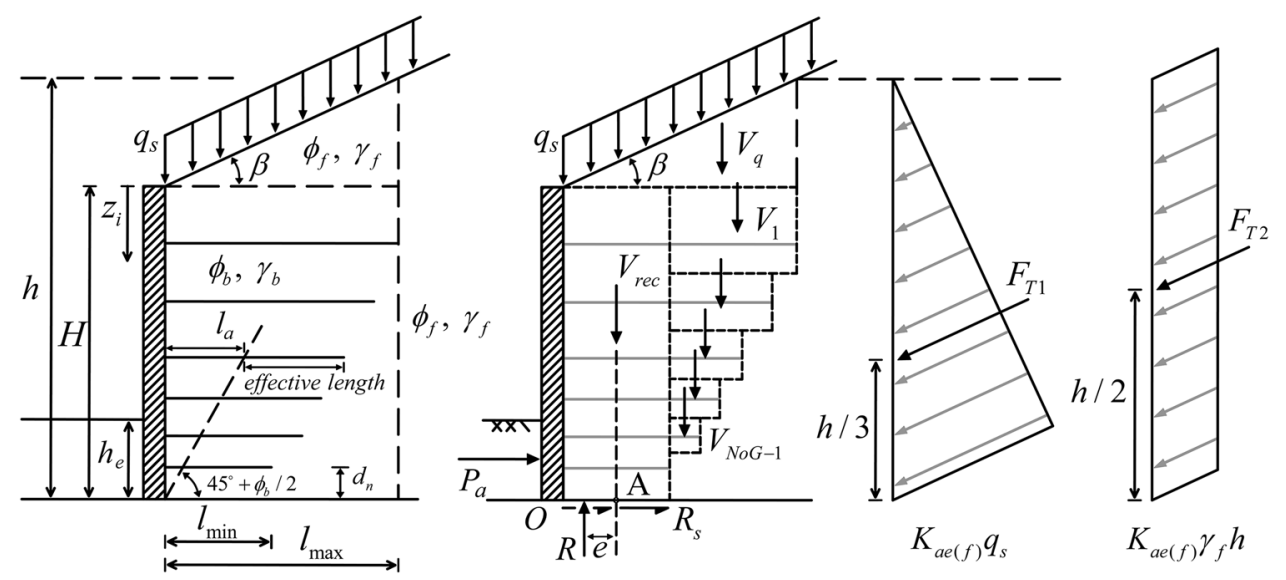

soil behind and on the top of the reinforced mass) respectively.

Regardless of type of reinforcement, any reinforced system should be checked for internal and external stability. The internal stability deals with interactions between reinforcements and the material in contact with them and mechanisms that lead to soil fracture and the associated rupture of the reinforcements. The external stability, on the other hand, deals with the behavior of the rigid body of reinforced-soil zone interacting with neighboring soil and the mechanisms that disturb its stability. The design of geosynthetic-reinforced soil walls is not considered safe until the safety factors against internal and external failure mechanisms are above the corresponding minimum values specified by codes.

Internal stability analysis of non-uniform lengths and spacing is exactly the same as that of uniform lengths and shapes. The summation of the weights $V_{\text {rec }}, V_{\mathrm{q}}$ and $V_{1}$ through $V_{\mathrm{NoG}-1}$, is the total weight of the soil within the reinforced zone where $N o G$ refers to the number of geosynthetic layers. Considering the reinforced system as a plane-strain problem, this weight is considered to act as a block. Since the wall embedment depth is small, the stabilizing effect of the passive pressure (moment) has been neglected in the analysis. The factors of safety against the above failure mechanisms are presented below.

- Safety factor against overturning It is assumed that, if overturning takes place, the whole reinforced zone will behave as a rigid body. Referring to Fig. 1, the safety factor against overturning is evaluated by considering moment equilibrium about point $O$. It can be calculated from:

$$
\begin{aligned}
F S_{\text {overturning }} & =\frac{\sum M_{\mathrm{Ro}}}{\sum M_{\mathrm{o}}} \\
& =\frac{\left(F_{\mathrm{T} 1} \times(h / 3)+F_{\mathrm{T} 2} \times(h / 2)\right)(\cos \beta)}{V_{\mathrm{rec}} \times\left(l_{\min } / 2\right)+V_{\mathrm{q}} \times\left(2 l_{\max } / 3\right)+\sum_{i=1}^{N o G-1}\left(V_{i} \times \frac{l_{i}+l_{\min }}{2}\right)+q_{\mathrm{s}} \times\left(l_{\max }^{2} / 2\right)}
\end{aligned}
$$

spacing. Details regarding this have been covered in other literature $[1,28]$.

Generally, three failure mechanisms are assessed in examining the external stability of retaining structures. In geosynthetic-reinforced earth wall systems, the sliding of the rigid body of reinforced-soil system, bearing capacity of the foundation soil below the reinforced zone and overturning of the reinforced-soil zone are considered to be these three failure mechanisms. Figure 1 shows the external forces in a geosynthetic-reinforced wall system. In the figure, $V_{i}$ refers to the weight of the soil enclosed by the associated geometric where $\sum M_{\mathrm{Ro}}$ and $\sum M_{\mathrm{o}}$ are the resisting and overturning moments respectively. The other parameters in Eq. 3 are as defined and indicted in Fig. 1.

- Safety factor against sliding Three relevant components are accounted for during the evaluation of safety against sliding. The first consists of the weight of the reinforced zone and all vertical forces acting above this zone. Interface friction angle between the soil and fabric, $\delta$, is the second component that needs consideration. The third components refers to all the driving 
lateral forces that try to cause sliding. The factor of safety against sliding can be expressed as:

$$
\begin{array}{r}
F S_{\text {sliding }}=\frac{\sum \text { horizontal resisting forces }}{\sum \text { horizontal driving forces }}=\frac{\sum P_{\mathrm{R}}}{\sum P_{\mathrm{d}}} \\
=\frac{\left(V_{\mathrm{rec}}+V_{\mathrm{q}}+\sum_{i=1}^{\text {NoG-1 }} V_{i}+q_{\mathrm{s}} \times l_{\max }\right) \times \tan \delta}{\left(F_{\mathrm{T} 1}+F_{\mathrm{T} 2}\right)(\cos \beta)}
\end{array}
$$

where $\sum P_{\mathrm{R}}$ and $\sum P_{\mathrm{d}}$ are resisting and driving forces respectively.

- Safety factor for bearing capacity: The reaction's eccentricity, $e$, from the centerline of the reinforced earth block, can be evaluated from moment equilibrium about point $A$ :

$e=\frac{\sum M_{\mathrm{d}}-\sum M_{\mathrm{R}}}{\sum V}$

In this study Meyerhof's equivalent-rectangular pressure distribution [29, 30] is used to calculate the bearing capacity of the foundation soil under eccentric load conditions. To stay in the conservative side of design, $l_{\min }$ is used in calculating the vertical stress acting on the foundation. For mild natural ground slopes (i.e. small angels of $\beta$ in Fig. 1), the vertical pressure $\sigma_{\mathrm{v}}$ can be calculated using the following equation:

$\sigma_{\mathrm{v}}=\left(V_{\mathrm{rec}}+V_{q}+\sum_{i=1}^{N o G-1} V_{i}\right) /\left(l_{\min }-2 e\right)$

Using the Terzaghi's equation [31] for a strip footing on a cohesionless soil and assuming $q$ as the surcharge associated with the soil to the left of the reinforced-soil, the ultimate bearing capacity can be calculated as:

$q_{\mathrm{ult}}=q N_{\mathrm{q}}+0.5 \gamma_{\mathrm{f}} N_{\mathrm{f}} l_{\min }$

The safety factor for bearing capacity is then obtained from:

\begin{tabular}{|c|c|c|c|c|}
\hline \multirow[t]{3}{*}{ Item } & \multicolumn{3}{|c|}{ Assumed cost factor } & \multirow{3}{*}{$\begin{array}{l}\text { Cost applied per unit } \\
\text { length of the wall }\end{array}$} \\
\hline & \multirow[t]{2}{*}{ Symbol } & \multicolumn{2}{|l|}{ Value } & \\
\hline & & Geogrid & Geotextile & \\
\hline Leveling pad & $C_{1}$ & $\$ 10 / \mathrm{m}$ & $\$ 10 / \mathrm{m}$ & $c_{1}$ \\
\hline Wall fill & $C_{2}$ & $\$ 3 / 1000 \mathrm{~kg}$ & $\$ 3 / 1000 \mathrm{~kg}$ & $c_{2} \times \frac{\gamma_{\mathrm{f}}}{g} \times\left(\operatorname{Vol}_{\text {reinforced zone }}\right)$ \\
\hline Geosynthetic & $C_{3}$ & $\$[\mathrm{Ta}(0.03)+2.0] \mathrm{m}^{2}$ & $\$[\mathrm{Ta}(0.03)+2.6] \mathrm{m}^{2}$ & $\sum_{i=1}^{N o G} c_{3} \times l_{i}$ \\
\hline MCU face unit* & $C_{4}$ & $\$ 60 / \mathrm{m}^{2}$ & 0 & $c_{1} \times H$ \\
\hline Engineering tests & $C_{5}$ & $\$ 10 / \mathrm{m}^{2}$ & $\$ 30 / \mathrm{m}^{2}$ & $c_{5} \times H$ \\
\hline Installation & $C_{6}$ & $\$ 50 / \mathrm{m}^{2}$ & $\$ 50 / \mathrm{m}^{2}$ & $c_{6} \times H$ \\
\hline
\end{tabular}

Table 1 Assumed cost factors (after Manahiloh et al. [1])

* The Modular Concrete Facing Units (MCU) are only applied for Geogrid type walls 


\section{Applying Design Constraints to the Objective Function}

For the sake of simplicity, a linear penalty function has been used in this study. The mathematical formulation for an objective function subject to seven constraints can be expressed as follows:

$\min f(x)$ subject to $g_{j} \leq 0 ; \quad j=1,2, \ldots, 7$

The modified objective function $\phi(\mathrm{x})$ can then be represented by:

$\phi(x)=f(x)[1+K \times C]$

where $K$ and $C$ are penalty parameters in which $K$ is a constant coefficient which increases the rate of penalty applied to the function and for most engineering problems $K=10$ is assumed appropriate. $C$ is a measure of violation defined as:

$C=\sum_{j=1}^{m} C_{j} \leftarrow \begin{cases}C_{j}=g_{j} & \text { if } \mathrm{g}_{j}>0 \\ C_{j}=0 & \text { if } \mathrm{g}_{j} \leq 0\end{cases}$

\section{Design Variables}

In traditional $H S A$, the variables are independent. Using each spacing, as an individual variable, results in a conflict during algorithm execution. Noting that the summation of all spacing values must be equal to the height of the wall, the algorithm conflict can systematically be avoided by introducing an additional constraint that restricts the summation of all spacing values to be equal to the height of the wall. However, it has been discovered that this method introduces additional computational effort. To overcome this difficulty, a vector that contains all the distances $\left(d_{n}\right)$ between consecutive geosynthetic layers is considered in each harmony as a single variable (S) as shown in Eq. (13).

$S=\left[d_{1}, d_{2} \cdots d_{n} \cdots d_{N o G+1}\right]$

The allocation of each value in this vector depends on the discretization of the acceptable range for spacing. It is also dependent on the algorithm's capability to search for combinations of spacing values whose summation equals to the height of the wall. The details are provided in the next sections.The other variables are the lengths of geosynthetic in each layer staring from top of the wall. Each harmony, therefore, consists of a vector of dependent variables for spacing and lengths of each layer as independent variables as shown in Eq. (14).

$H=\left[S l_{1} l_{2} \cdots l_{n-1} l_{n} \mid C\right]$

In the calculation for spacing values between adjacent layers of geosynthetic layers, the spacing associated with each layer is assumed as the average of distances above and below each layer. This assumption is indicated in Eq. (15).

$S_{n}=\frac{d_{n}+d_{n+1}}{2}$

This value is modified for the first and last layers of geosynthetics to account for absence of adjacent layer of geosynthetics above and below those layers respectively.

\section{Implementation of Harmony Search Algorithm}

The process of finding a pleasing and ear-catching harmony in music is analogous to finding the optimality in an optimization process [33]. HSA is known as one of the powerful metaheuristic optimization methods inspired by improvisation ability of musicians that involves less mathematical efforts and highly accurate results. The base structure of this algorithm has been presented by Geem [34]. Since then, efforts have been made to modify the functionality of the base algorithm. In this study an improved harmony search, proposed by Mahdavi et al. [22], is extended and implemented to the optimization of the cost associated with the construction of geosynthetic-reinforced earth walls.

The steps involved in the IHS are presented in the flowchart shown in Fig. 2. As indicated in the flowchart, the optimization program is initiated with a set of random harmonies (also called solution vectors or individuals) stored in a matrix called harmony memory $(H M)$. The term "harmony" refers to solution vectors that contain sets of decision variables. $H S$ algorithms use three mechanisms to produce a new harmony: memory consideration, random choosing, and pitch adjustment. The basic $H S$ algorithm uses a constant probability and a fixed value to pitch-adjust the variables inside the new harmonies. IHS, on the other hand, employs interactive functions to improve the convergence of the harmonies to the optimized solution. In each step, every new solution that is better than any of the stored harmonies from previous steps takes the place of the worst solution in the HM until termination criteria is satisfied. In order to fit the dependent variables into the $H M$ and assign a random neighborhood for them, a new procedure is developed as discussed below.

\section{Step 1: Introduction of the Optimization Program and Parameters for the Algorithm}

In this step, a set of specific parameters is introduced to the IHSA. Some of the parameters are:

i. The harmony memory size (HMS). This determines the number of individuals (solution vectors) in the $H M$. For a given wall, in this work, 10 solution vectors are introduced to build the harmony memory. 
Fig. 2 IHS Algorithm flowchart

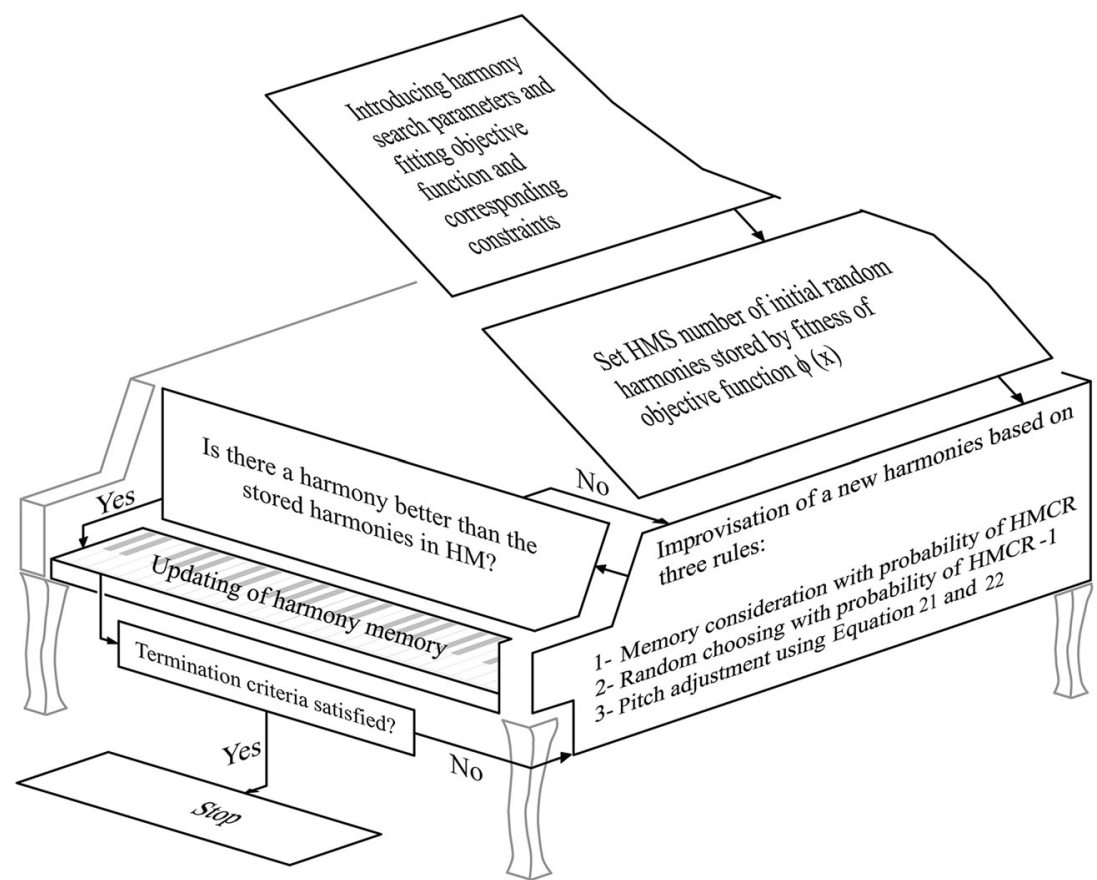

ii. The harmony memory consideration rate (HMCR). This parameter is utilized while decision is made to choose new variables from the $H M$ or to assign new arbitrary values.

iii. The pitch adjustment rate $(P A R)$. PAR, increasing functionally with iteration, is used to decide the adjustments of some decision variables selected from memory. The IHSA expects the definition of minimum and maximum $P A R$ values to this function.

iv. The bandwidth function $(B W)$. This function determines the range of the adjustment that occurs to the variables in each iteration. A set of minimum and maximum bandwidth values $\left(B W_{\min }\right.$ and $\left.B W_{\max }\right)$ must be introduced to this function. The value of this function decreases from $B W_{\max }$ in first iteration to $B W_{\min }$ in last iteration.

v. The maximum number of iteration $(N I)$ which is also called Stopping or Termination Criteria.

vi. The permutation evaluation rate $(P E R)$. This parameter is useful in deciding whether different permutations of the solution vector, holding information about the non-uniform geosynthetic spacing values, are considered or not. This parameter is not included in the traditional HSA and HIS. It is proposed, by this work, in order to increase the probability of considering rare occurrences for vector $\mathbf{S}$ and to evaluate its different permutations.

The values attained by the parameters $H M C R, P A R_{\min }$, $P A R_{\max }, B W_{\text {min }}, B W_{\text {max }}$ and $H M S$ differ from one problem to another and can affect the convergence of the HSA to the optimum solution. Lower values attained by the PAR indicate an increased chance of adjusting one parameter without changing the others. However, $B W$ must take bigger values for the first few iterations in order to ensure the creation of diversified solution vectors by the algorithm [22]. Setting appropriate values for these parameters will also enable the algorithm to avoid getting trapped in a local optimum. Lee et al. [16] proposed a value between 0.7 and 0.95 for HMCR; 0.2 and 0.5 for PAR; and 10 and 50 for $H M S$ to achieve a good performance in the traditional HSA. In IHS Algorithm the value of $P A R$ and $B W$ varies with progressive iterations [22].

The optimization problem is initially presented as minimizing $F\left(\mathbf{S}, l_{1}, l_{2}, \ldots, l_{N}\right)$ which is the objective function. The vector $\mathbf{S}$ and geosynthetic lengths are the decision variables where $\mathbf{S}=\left[d_{1}, d_{2} \cdots d_{n}, d_{N o G+1}\right] \quad$ and $l=\left\{l_{N} \mid N=1,2, \ldots, N o G\right\}$. Therefore, the number of decision variables $(N o V)$ is equal to the number of geosynthetic layers plus one (i.e. Eq. (16). Each length value is an independent variable which is represented by its layer number and the additional variable $S$ is an array made up of the inter-dependent spacing values.

$N o V=N o G+1$

In this paper the lower and upper bounds for the decision variables of type $l$ (i.e. reinforcement length) are set to $1 \mathrm{~m}$ and $10 \mathrm{~m}$ respectively. Applying the terms upper and lower bound for the array $\mathbf{S}$ does not make a clear sense as $\mathbf{S}$ contains a set of inter-dependent spacing-related variables $(d)$. However, the lower and upper bounds for the dependent variables can be defined. The minimum and maximum values for the individual spacing values are considered to be $0.2 \mathrm{~m}$ and $1.5 \mathrm{~m}$, respectively. These 
numbers were picked to be consistent, for result comparison purposes, with Manahiloh et al. [1]. In addition, these limit values can be applied to $d$-values so that the spacing values are allowed to vary within a specified range.

One of the challenging tasks, faced in this study, was how to assign the inter-dependent $d$ values and form an optimized vector $\mathbf{S}$. One way this task could be accomplished is by combining the gradient descent method with Harmony Search Algorithm and finding the optimum value of the $\mathbf{S}$ vector. Another, yet simpler, way is to discretize the domain of $d$ into a few finite values and design a probabilistic method to find the optimum vector $\mathbf{S}$. In the later approach, any possible combination of the discretized values of the domain - with a fixed summation equaling to the height of the wall-will have an equal probability of being chosen to make up the vector $\mathbf{S}$. To elaborate on this, let's assume that the continuous range of $d$ values (i.e. [0.2, 1.5]) is to be discretized into a certain number of distances (i.e. NoD). This way, the difference between each discretized value in the given range is kept constant and less than a specified value. In this paper, $D V$ refers to this value and the $N o D$ is then given as:

$N o D=\left|\frac{S_{\max }-S_{\min }+D V}{D V}\right|$

The exact value of the difference between each discretized value within the domain is found by dividing the range by $N o D$. Once calculated, the discretized values are set in a vector. A random combination of the $N o G+1$ number of the discretized values - with a fixed summation equaling to the height of the wall—can be assumed as a possible solution for the vector $\mathbf{S}$.

The values for the length of geosynthetic layers (i.e. $l$ values) are independently selected with a stochastic process. The ranges from which the algorithm picks values for the $N o G$ and $l$ values are set based on experience and validated literature.

\section{Step 2: Initialization of Initial Harmony Memory (HM)}

In this step, the initial $H M$ matrix is populated with as many randomly generated individuals as the $H M S$ and the corresponding Objective Function value of each set of random individuals $F\left(\mathbf{S}, l_{1}, l_{2}, \ldots, l_{N}\right)$. The initial harmony memory is formed as follows:

$$
H M=\left[\begin{array}{cccc|c}
\mathbf{S}^{1} & l_{1}^{1} & \ldots & l_{N}^{1} & F^{1} \\
\vdots & \vdots & \ldots & \ldots & \vdots \\
\mathbf{S}^{H M S-1} & l_{1}^{H M S-1} & \ldots & l_{N}^{H M S-1} & F^{H M S-1} \\
\mathbf{S}^{H M S} & l_{1}^{H M S} & \ldots & R_{N}^{H M S} & F^{H M S}
\end{array}\right]
$$

After the variables are assigned, the IHS algorithm solves the problem such that the Objective Function is optimized by minimizing its value. Upon the process of optimization, to minimize the Objective Function, Cost values associated with each set of individuals are arranged in a numerically ascending order.

\section{Step 3: Improvisation for a New Harmony}

In this step, a New Harmony vector $F^{\prime}\left(\mathbf{S}^{\prime}, l_{1}^{\prime}, l_{2}^{\prime}, \ldots, l_{N}^{\prime}\right)$, is improvised based on four mechanisms: (1) Memory Consideration; (2) Random Selection; (3) Pitch Adjustment; and (4) Permutation evaluation.

\section{Harmony Memory Consideration}

HMCR and 1-HMCR are defined as the rate of choosing one value from previously stored values in $H M$ and the rate of randomly selecting one value from the possible range for variables respectively. For the $i$ th iteration and the $j$ th variable in each harmony vector we can write the following:

For $j=1$ :

$\mathbf{S}_{i}^{\prime} \leftarrow\left\{\begin{array}{l}\mathbf{S}_{i}^{\prime} \in\left\{\mathbf{S}^{1}, \mathbf{S}^{2}, \ldots, \mathbf{S}^{H M S}\right\} \text { with probability HMCR } \\ \mathbf{S}^{\prime} \in \text { A new combination of } H \text { with probability (1-HMCR) }\end{array}\right.$

For $j>1$ :

$l_{i j}^{\prime} \leftarrow\left\{\begin{array}{l}l_{i j}^{\prime} \in\left\{l_{j}^{1}, l_{j}^{2}, \ldots, l_{j}^{H M S}\right\} \text { with probability HMCR } \\ l_{i}^{\prime} \in\left[l_{\min }, l_{\max }\right] \text { with probability (1-HMCR) }\end{array}\right.$

For an instance, assuming $H M C R$ equal to $0.95, H S A$ selects the new variables from values stored in $H M$ with a probability of $95 \%$.

\section{Pitch Adjustment}

In this step, each decision variable associated with the new individual is pitch-adjusted with a probability that was assigned to that variable. The main difference between $H S A$ and $I H S$ is observed when the pitch adjustment rate $(P A R)$ is assigned to each variable in each step. In $I H S$ a lower and upper level is defined for $P A R$. With progressive iterations, $P A R$ linearly changes from low to high values. Variation of $P A R$ with iteration in $I H S$ was expressed by Mahdavi et al. [22] as:

$P A R_{i}=P A R_{\min }+\frac{P A R_{\max }-P A R_{\min }}{N I} \times i$

where $i$ is the iteration number and $N I$ is the maximum number of iterations as defined previously. The justification 
for this linear relationship was that small $P A R$ values significantly increase the number of iterations [22]. However, small $P A R$ values are essential in first iterations to prevent the algorithm from being trapped in local optimums.

IHS bases itself on the dynamic interaction between $P A R$ and $B W$. This dynamic interaction is manifest as the magnitude (distance) of the adjustment made to each variable, on each harmony, in the Pitch Adjustment operator. Generating high values of $B W$ during the first iterations helps the algorithm to evaluate higher distances. This in turn augments the search capability of the algorithm. As the number of iterations increases, the system examines closer neighborhoods (distances from the newly obtained and assigned variables) and optimize their results further. The values of the $B W$ which are bounded by lower and upper limits (i.e. $B W_{\min }$ and $B W_{\max }$ ), are set to decrease exponentially from $B W_{\max }$ to $B W_{\min }$. Mahdavi et al. [22] proposed the following equation for $B W$ in each iteration:

$B W_{i}=B W_{\max }+\exp (c \times i)$

where $\mathrm{c}$ is a coefficient given by:

$c=\frac{\ln \left(\frac{B W_{\min }}{B W_{\max }}\right)}{N I}$

Pitch Adjustment is applied to two kinds of variables. These are: (i) A vector of dependent variables (i.e. vector $\mathbf{S}$ made of the spacing values), and (ii) A set of independent variables (i.e. lengths).

Pitch adjustment for the vector $S$ In this study, the values of 0.35 and 0.99 are considered for $P A R_{\min }, P A R_{\max }$, respectively. Having calculated the $P A R_{i}$, within the range $\left[P A R_{\min }\right.$, $\left.P A R_{\max }\right]$, for each iteration from Eq. (21), one can adjust the values of the vector $\mathbf{S}$ with the probability of $P A R_{i}$, as:

Pitch adjusting decision for $\mathbf{S}_{i}^{\prime}$

$\leftarrow \begin{cases}\text { Yes } & \text { With probability } P A R_{i} \\ N o & \text { With probability } 1-P A R_{i}\end{cases}$
Two simple methods can be adopted to define neighborhoods for vectors which are made of inter-dependent individual variables whose summation must remain constant (e.g. Vector $\mathbf{S}$ ). The first method uses a small noise vector of the same number of elements and adds these elements with that of the original vector. Assume that $\mathbf{S}_{S+N}$ is a vector made by summing elements of the random noise vector (scaled by $B W 1$ ) and elements of vector $\mathbf{S}$.

$\mathbf{S}_{S+N}=\mathbf{S}+B W 1_{i} \times($ a random noise vector $)$

where $B W 1_{i} \in\left[B W 1_{\min }, B W 1_{\max }\right]$ is distance (neighborhood) bandwidth for vector $\mathbf{S}$ and can be calculated from Eq. (22) for each iteration. $B W 1_{i}$ is introduced to the $I H S$ in order to assist the algorithm pick an optimal path in the close neighborhoods of vector $\mathbf{S}$. Note that the sum of the elements of the vector defined in Eq. (25) does not add up to a value equal to the height of the wall. In order to bring the summation to a value equaling the height of the wall, one needs to assess the locus of such vectors which takes the shape of a hyper-diamond. If the sum of the elements of $\mathbf{S}_{S+N}$ is designated by $V_{\text {sum }}$, a new pitch adjusted neighborhood for the vector $\mathbf{S}$ (i.e. $\mathbf{S}_{i}^{\prime}$ ) located on the hyperdiamond can be defined as:

$\mathbf{S}_{i}^{\prime} \leftarrow=\left(S_{S} \mathbf{S}_{S+N}\right) / V_{\text {sum }}$

where $S_{s}$ represents the sum of the elements of vector $\mathbf{S}$.

This method, however, does not accommodate for any definite arrangement and order in framing the neighborhoods. There is an alternative approach that enables the algorithm to have an arranged set of vectors. In this method the neighborhoods of a vector can be defined by adding a set of defined vectors that add a small value to some elements and subtract it from other elements so as to keep the summation of the elements fixed. Each row of the matrix presented below shows some vectors that can be used to manipulate vector $\mathbf{S}$ and produce a new neighborhood:

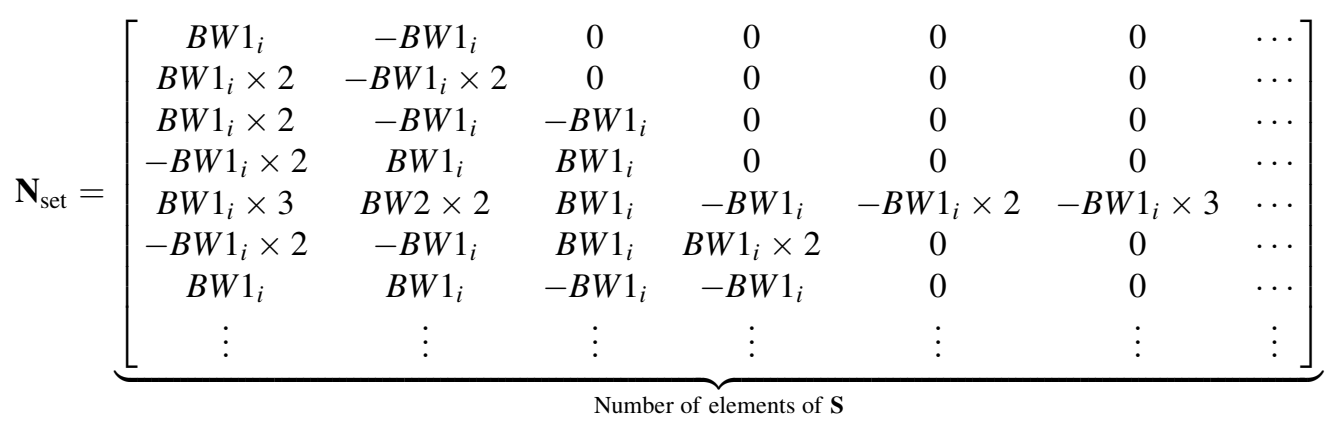


In Eq. (27), each row of $\mathbf{N}_{\text {set }}$ is a vector that contains scaled $B W 1$ values that can be used in defining a neighborhood for vector $\mathbf{S}$. Each row can be added to (or subtracted from) vector $\mathbf{S}$ to produce a new neighborhood. All permutations of the elements in each row of $\mathbf{N}_{\text {set }}$ need to be considered in the calculation in order to have accurate estimate of the neighborhood vectors. Similar to the first method discussed above, this approach assigns values for $B W I_{i}$ within a range bounded by a minimum and maximum. In this study the lower and upper limits for $B W 1$ are set to 0.009 and 0.2 respectively. These boundary values are set to attain an increased accuracy while running iterations for the spacing values that add up to give the height of the wall. Using the second approach, a set of random neighborhoods for the vector $\mathbf{S}$ can be generated using the following equation.

$\mathbf{S}_{i}^{\prime} \leftarrow=\mathbf{S}+N_{\text {set }}$

In this paper, all close neighborhoods are: generated using the second method; evaluated with the probability of $P A R_{i}$; and stored in a matrix ready to be evaluated with other adjusted harmonies.

Pitch adjustment for $l_{N}$ The values of $P A R_{\min }$ and $P A R_{\max }$ are the same for independent variables (lengths). Pitch adjustment for the lengths is done with the probability of $P A R_{i}$ :

Pitch adjusting decision for $l_{i}^{\prime}$

$\leftarrow\left\{\begin{array}{l}\text { Yes } \quad \text { With probability } P A R_{i} \\ \text { No } \quad \text { With probability } 1-P A R_{i}\end{array}\right.$

The lengths are modified to their neighboring values with the probability of $P A R 1$. For the problem discussed in this paper, Pitch Adjustment is applied for length $\left(l_{i}\right)$ as described by the following expression:

$l_{i}^{\prime} \leftarrow=l_{i}^{\prime} \pm$ (a random value) $\times B W 2_{i}$

where $B W 2_{i}$ for each step is calculated from Eq. (22). The values of $B W 2_{\min }$ and $B W 2_{\max }$ are given by Eq. (31).

$B W 2_{\min }=0.009$

$B W 2_{\max }=0.05 \times\left(l_{\max }-l_{\min }\right)$

where $l_{\min }$ and $l_{\max }$ are the lower and upper limits for the range defined for lengths of geosynthetics which are equal to 1 and $10 \mathrm{~m}$, respectively. The random value in Eq. (30) is determined using the Gaussian Membership Function which covers a higher range for the random value and gives a small possibility to higher values to be chosen. If Pitch Adjustment causes a variable to fall outside the given range, an alternative value must be replaced for the outlier. This alternative value can be the minimum or maximum of the range assigned to the variable.

\section{Permutation Evaluation for the Vector $S$}

In this study, a set of random number of permutations of the vector $\mathbf{S}$ is also evaluated with the probability of $P E R$ to increase the chance of the $\mathbf{S}$ vectors that have small probability of random selection. This evaluation is done after Pitch Adjustment for the produced $\mathbf{S}$ vectors. The number of these permutations is randomly chosen from 1 to 10 .

\section{Step 4: Updating the Harmony Memory}

If the newly generated Harmony Vector is better than any of the stored Harmony Vectors in the $H M$ (i.e. results in a better Objective Function value than that for the stored individuals), it will replace the old stored vector in the $H M$. Otherwise, the algorithm enters the next loop (iterating between Steps 3 and 4) without any replacement.

\section{Step 5: Evaluation of the Termination Rule}

Steps 3 and 4 continue to repeat until the Termination Rule is satisfied. The last solution vector that meets the requirements of the Termination Rule is reported as the optimized solution for the problem under consideration. Undoubtedly, the maximum number of generations could be different from problem to problem depending on the desired accuracy. In this study, The Termination rule is considered to be satisfied, when the values of Cost Function, $F$, are equal up to ten decimal places for 200 consecutive iterations. Figure 3 shows the reduction in cost with iterations for 9 meter Geogrid-Wrap Wall with $A_{\mathrm{m}}=0$ and overburden pressure equal to $q_{\mathrm{s}}=10$. It can be seen that the Mean Cost Values in the $H M$ converge to the best cost, after 300 iterations. Further iteration causes slight changes in the variables, however, the changes in cost function will be insignificant.

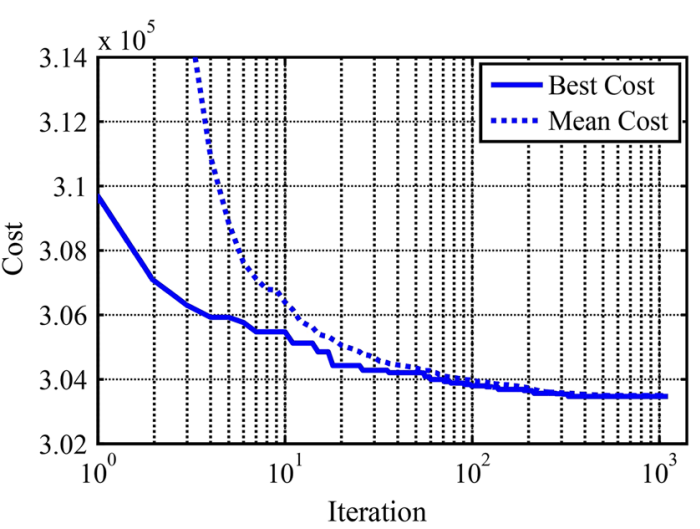

Fig. 3 Reduction in cost with iterations for 9 meter Geogrid-Wrap Wall with $A_{\mathrm{m}}=0, q_{\mathrm{s}}=10$ 


\section{Results and Discussions}

As was discussed in Sect. 6, an improved harmony search (IHS) was modified into a novel searching algorithm by incorporating a permutation-based optimization technique to handle non-uniform length and spacing of geosynthetic reinforcements. The analyses discussed herein and the associated results were compared to the work by Manahiloh et al. [1]. As such, the parameters, system geometry and load configurations were made, by design, similar to that of Manahiloh et al. The input parameters used in defining each problem are presented in Table 2.

Table 3 shows the summary of results, obtained for uniform length and spacing values, that had been referred to in comparing the results of this study with that of Manahiloh et al. [1].

The results obtained for problems solved in different modes (i.e. Geotextile-wrap, Geogrids with; Static loading, Dynamic(seismic) loads) and their comparison with the results obtained by Manahiloh et al. [1] are presented in Tables 4, 5, 6, 7, 8, 9 .

The results for No Earthquake and No Surcharge Load (i.e. $A_{\mathrm{m}}=0, q_{\mathrm{s}}=0$ ) presented in Tables 4 and 5 indicates that the amount of saving increases as the height of the wall increases. As was expected, the cost savings were higher for larger wall heights that involve larger volume of excavation. For smaller heights, the amount of saving is higher for Geotextile-wrap walls as compared to that of Geogrid-reinforced walls. The tensile strength required for the reinforcement was found to be higher for he cases involving taller wall heights. A decreasing trend, for both spacing and length values, was observed from upper to lower geosynthetic layers.

As shown in Tables 6 and 7, higher saving was obtained for the case of No Earthquake and Surcharge of $10 \mathrm{kPa}$ $\left(A_{\mathrm{m}}=0\right.$ and $q_{\mathrm{s}}=10 \mathrm{kPa}$ ) as compared to the cases presented in Tables 4 and 5. A general increasing trend in the percentage of cost reduction was observed.
Table 2 Input design parameters (after Manahiloh et al.)

\begin{tabular}{ll}
\hline Parameter & value \\
\hline Height of Wall $(H)$ & $5-9 \mathrm{~m}$ \\
Minimum embankment of the fill $\left(h_{\mathrm{e}}\right)$ & 0.45 \\
Angle of internal friction of the backfill $\left(\phi_{\mathrm{f}}\right)$ & $30^{\circ}$ \\
Unit weight of the backfill $\left(\gamma_{\mathrm{f}}\right)$ & $18 \mathrm{kN} / \mathrm{m}^{3}$ \\
Angle of internal friction of the fill $\left(\phi_{\mathrm{b}}\right)$ & $35^{\circ}$ \\
Unit weight of the fill $\left(\gamma_{\mathrm{b}}\right)$ & $20 \mathrm{kN} / \mathrm{m}^{3}$ \\
Ultimate tensile strength of the geosynthetic $\left(T_{\mathrm{u}}\right)$ & $<60 \mathrm{kN} / \mathrm{m}$ \\
Allowable tensile strength of the geosynthetic $\left(T_{\mathrm{a}}\right)$ & $T_{\mathrm{a}}=T_{\mathrm{u}} / 1.5 \mathrm{kN} / \mathrm{m}$ \\
Surcharge slope angle $(\beta)$ & $0^{\circ}$ \\
Minimum length of the reinforcement $\left(l_{\mathrm{e} \text { min }}\right)$ & $1.0 \mathrm{~m}$ \\
\hline
\end{tabular}

Table 3 Summary of results for uniform length and spacing values (modified from Manahiloh et al. [1])

\begin{tabular}{|c|c|c|c|c|c|c|c|c|c|c|c|c|}
\hline & \multicolumn{4}{|c|}{$A_{\mathrm{m}}=0, q_{\mathrm{s}}=0$} & \multicolumn{4}{|c|}{$A_{\mathrm{m}}=0, q_{\mathrm{s}}=10 \mathrm{kPa}$} & \multicolumn{4}{|c|}{$A_{\mathrm{m}}=0.05, q_{\mathrm{s}}=0$} \\
\hline \multicolumn{13}{|c|}{ Geotextile } \\
\hline $\begin{array}{l}H_{\mathrm{t}} \\
\quad(\mathrm{m})\end{array}$ & $N o G$ & $l(\mathrm{~m})$ & $\begin{array}{l}T_{\mathrm{a}}-\max (\mathrm{KN} / \\
\mathrm{m})\end{array}$ & $\begin{array}{l}\text { Total cost } \\
(\$)\end{array}$ & $\mathrm{No} G$ & $L(\mathrm{~m})$ & $\begin{array}{l}T_{\mathrm{a}}-\max (\mathrm{KN} / \\
\mathrm{m})\end{array}$ & $\begin{array}{l}\text { Total cost } \\
(\$)\end{array}$ & $N o G$ & $l(\mathrm{~m})$ & $\begin{array}{l}T_{\mathrm{a}}-\max (\mathrm{KN} / \\
\mathrm{m})\end{array}$ & $\begin{array}{l}\text { Total cost } \\
\text { (\$) }\end{array}$ \\
\hline 5 & 3 & 3.23 & 26.5 & 116826.2 & 3 & 3.24 & 30 & 117066 & 3 & 3.62 & 32 & 120390.5 \\
\hline 7 & 5 & 4.34 & 38.5 & 175045.2 & 6 & 4.43 & 36.75 & 178993.7 & 6 & 4.83 & 40 & 184432.2 \\
\hline 9 & 10 & 5.59 & 37.8 & 253864.8 & 11 & 5.62 & 37.1 & 258287.4 & 12 & 6.15 & 37.84 & 271914.3 \\
\hline \multicolumn{13}{|l|}{ Geogrid } \\
\hline $\begin{array}{l}H_{\mathrm{t}} \\
\quad(\mathrm{m})\end{array}$ & $N o G$ & $L(\mathrm{~m})$ & $\begin{array}{l}T_{\mathrm{a}}-\max (\mathrm{KN} / \\
\mathrm{m})\end{array}$ & $\begin{array}{l}\text { Total cost } \\
\text { (\$) }\end{array}$ & $N o G$ & $L(\mathrm{~m})$ & $\begin{array}{l}T_{\mathrm{a}}-\max (\mathrm{KN} / \\
\mathrm{m})\end{array}$ & $\begin{array}{l}\text { Total cost } \\
(\$)\end{array}$ & $N o G$ & $l(\mathrm{~m})$ & $T_{\mathrm{a}}$ & $\begin{array}{l}\text { Total cost } \\
\text { (\$) }\end{array}$ \\
\hline 5 & 3 & 3.233 & 26.5 & 159262.7 & 3 & 2.238 & 30 & 159510.6 & 3 & 3.62 & 32 & 162693.4 \\
\hline 7 & 5 & 4.341 & 38.5 & 232052.6 & 6 & 4.43 & 36.75 & 235405.1 & 6 & 4.83 & 40 & 240560.5 \\
\hline 9 & 10 & 5.59 & 37.8 & 322755.3 & 11 & 5.626 & 37.1 & 326459.7 & 12 & 6.15 & 37.84 & 338650.2 \\
\hline
\end{tabular}


Table 4 Optimum design values for Geotextile-wrap walls $A_{\mathrm{m}}=0, q_{\mathrm{s}}=0$

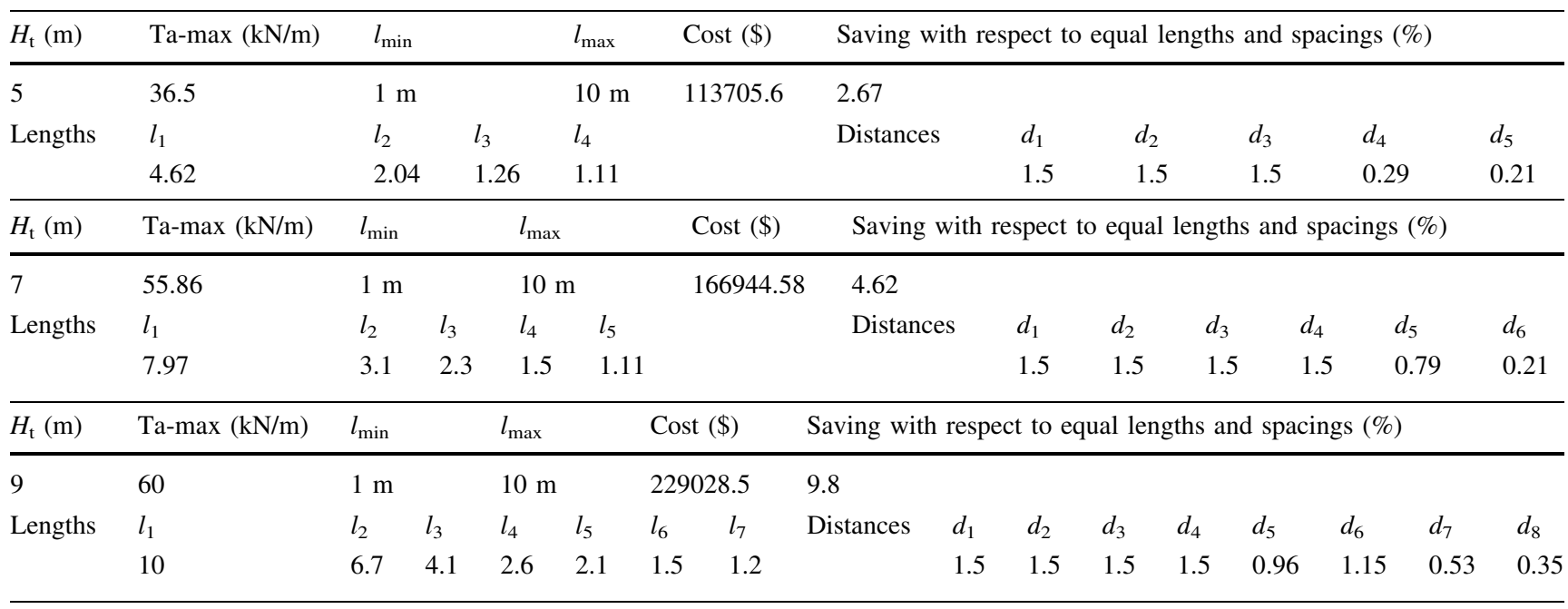

Table 5 Optimum design values for Geogrid-reinforced walls $A_{\mathrm{m}}=0, q_{\mathrm{s}}=0$

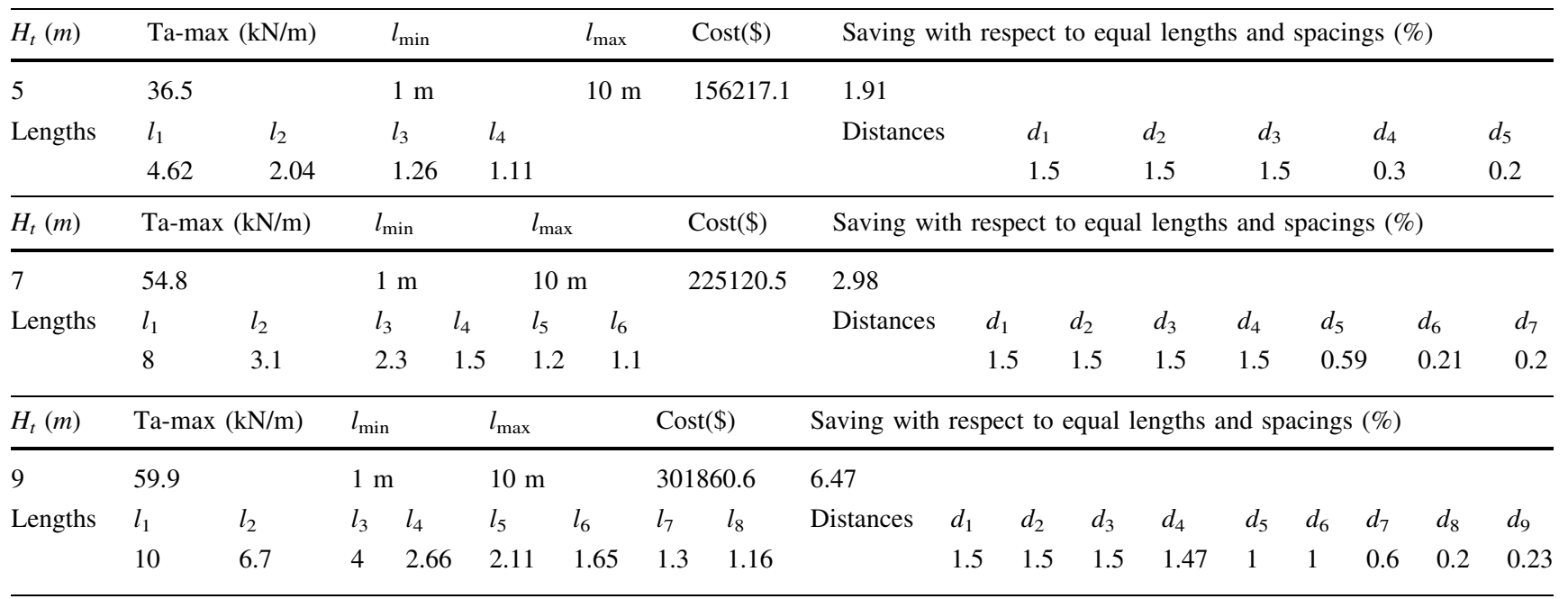

Table 6 Optimum design values for Geotextile-wrap walls $A_{\mathrm{m}}=0, q_{\mathrm{s}}=10 \mathrm{kPa}$

\begin{tabular}{|c|c|c|c|c|c|c|c|c|c|c|c|c|c|c|c|c|c|}
\hline \multirow{4}{*}{$\begin{array}{l}H_{\mathrm{t}}(m) \\
5 \\
\text { Lengths }\end{array}$} & \multicolumn{2}{|c|}{ Ta-max $(\mathrm{kN} / \mathrm{m})$} & \multicolumn{3}{|c|}{$l_{\min }$} & \multirow{2}{*}{$\frac{l_{\max }}{10 \mathrm{~m}}$} & Cost $(\$)$ & \multicolumn{10}{|c|}{ Saving with respect to uniform lengths and spacing (\%) } \\
\hline & 40 & & & $\mathrm{~m}$ & & & 115006.56 & 1.76 & & & & & & & & & \\
\hline & $l_{1}$ & $l_{2}$ & $l_{3}$ & & $l_{4}$ & & & Distanc & & $d_{1}$ & & $d_{2}$ & & $d_{3}$ & $d_{4}$ & & $d_{5}$ \\
\hline & 5.1 & 2.1 & & 38 & 1.11 & & & & & 1.33 & & 1.49 & & 1.48 & 0.5 & & 0.2 \\
\hline$H_{\mathrm{t}}(m)$ & \multicolumn{2}{|c|}{ Ta-max $(\mathrm{kN} / \mathrm{m})$} & \multicolumn{3}{|c|}{$l_{\min }$} & $l_{\max }$ & Cost $(\$)$ & \multicolumn{10}{|c|}{ Saving with respect to uniform lengths and spacing (\%) } \\
\hline 7 & 60 & & $1 \mathrm{r}$ & & & $10 \mathrm{~m}$ & 167738.5 & 6.29 & & & & & & & & & \\
\hline \multirow[t]{2}{*}{ Lengths } & $l_{1}$ & $l_{2}$ & $l_{3}$ & $l_{4}$ & & $l_{5}$ & & Distanc & & $d_{1}$ & $d_{2}$ & & $d_{3}$ & $d_{4}$ & $d_{5}$ & & $d_{6}$ \\
\hline & 8.1 & 3.1 & 2.3 & 1.5 & & 1.12 & & & & 1.49 & 1. & & 1.49 & 1.47 & 0.8 & & 0.22 \\
\hline$H_{\mathrm{t}}(m)$ & \multicolumn{2}{|c|}{ Ta-max $(\mathrm{kN} / \mathrm{m})$} & \multicolumn{2}{|l|}{$l_{\min }$} & \multicolumn{2}{|c|}{$l_{\max }$} & Cost $(\$)$ & \multicolumn{10}{|c|}{ Saving with respect to uniform lengths and spacing (\%) } \\
\hline 9 & 60 & & $1 \mathrm{~m}$ & & 101 & & 231288.1 & 10.45 & & & & & & & & & \\
\hline \multirow[t]{2}{*}{ Lengths } & $l_{1}$ & $l_{2}$ & $l_{3}$ & $l_{4}$ & $l_{5}$ & $l_{6}$ & $l_{8}$ & Distances & $d_{1}$ & $d_{2}$ & $d_{3}$ & $d_{4}$ & $d_{5}$ & $d_{6}$ & $d_{7}$ & $d_{8}$ & $d_{9}$ \\
\hline & 10 & 7.5 & 3.49 & 2.74 & 2.2 & 1.59 & 1.17 & & 1.5 & 1.5 & 1.5 & 1.4 & 0.88 & 1.14 & 0.54 & 0.33 & 0.2 \\
\hline
\end{tabular}


Table 7 Optimum design values for Geogrid-reinforced walls $A_{\mathrm{m}}=0, q_{\mathrm{s}}=10 \mathrm{kPa}$

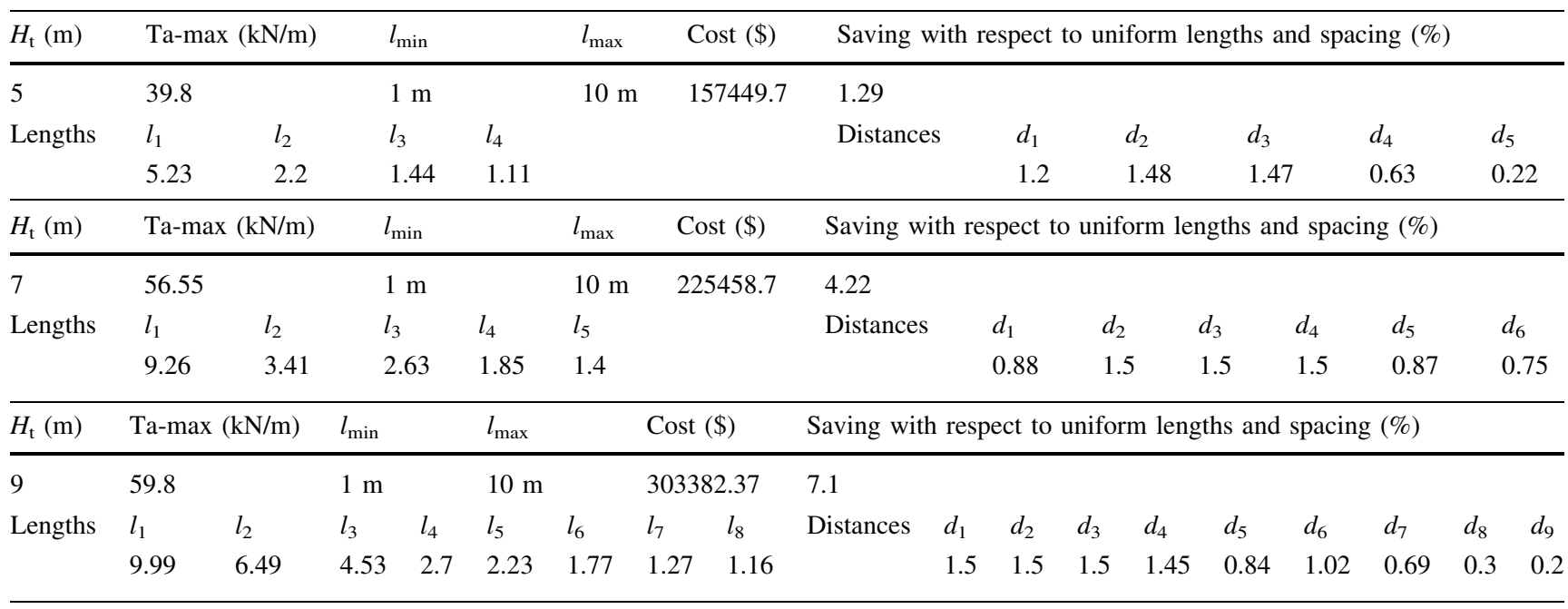

Table 8 Optimum design values for Geotextile-wrap walls $A_{\mathrm{m}}=0.05, q_{\mathrm{s}}=0$

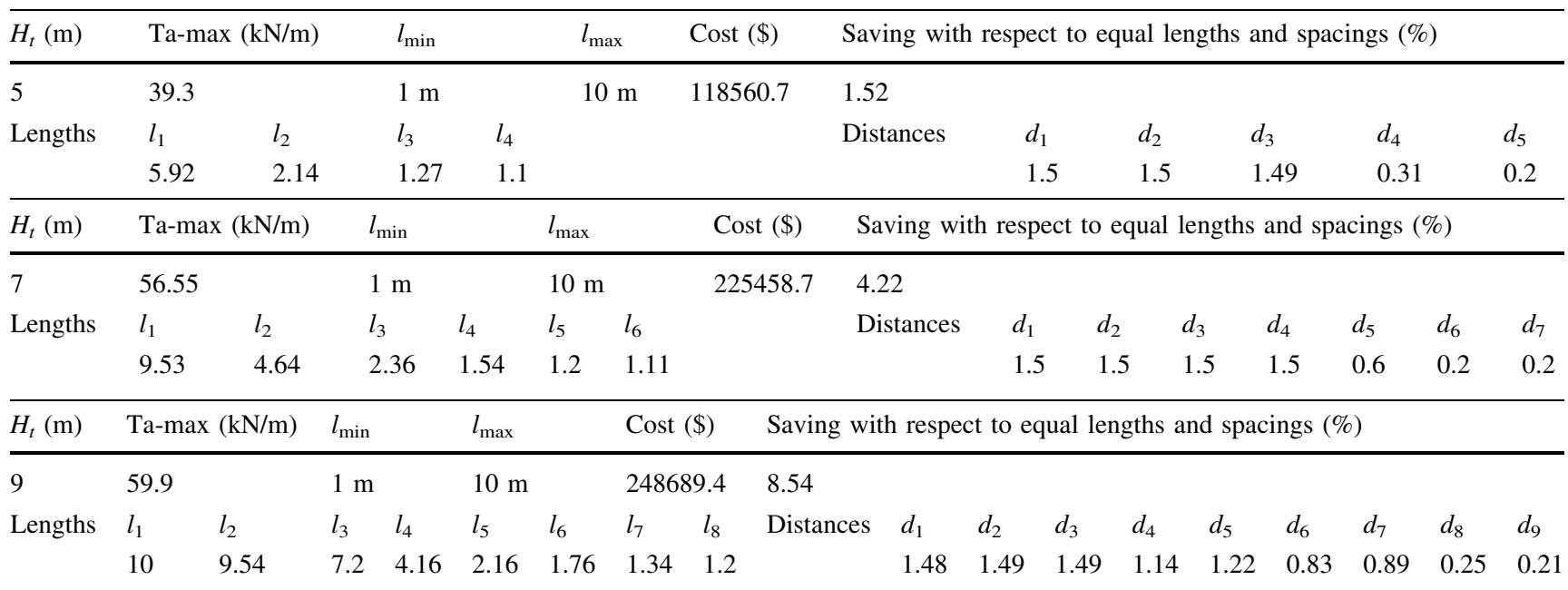

Table 9 Optimum design values for Geogrid-reinforced walls $A_{\mathrm{m}}=0.05, q_{\mathrm{s}}=0$

\begin{tabular}{|c|c|c|c|c|c|c|c|c|c|c|c|c|c|c|c|c|c|c|}
\hline \multirow{2}{*}{$\frac{H_{\mathrm{t}}(\mathrm{m})}{5}$} & \multicolumn{2}{|c|}{ Ta-max $(\mathrm{kN} / \mathrm{m})$} & \multicolumn{2}{|c|}{$l_{\min }$} & \multicolumn{2}{|r|}{$l_{\max }$} & \multicolumn{3}{|c|}{ Cost $(\$)$} & \multicolumn{9}{|c|}{ Saving with respect to equal lengths and spacings (\%) } \\
\hline & \multicolumn{2}{|c|}{39.34} & \multicolumn{2}{|c|}{$1 \mathrm{~m}$} & \multicolumn{2}{|r|}{$10 \mathrm{~m}$} & \multicolumn{2}{|c|}{160904.7} & & \multicolumn{9}{|l|}{1.1} \\
\hline & $l_{1}$ & $l_{2}$ & $l_{3}$ & $l_{4}$ & & & & & Distances & $d_{1}$ & & $d_{2}$ & & $l_{3}$ & $d_{4}$ & & $d_{5}$ & \\
\hline & 5.9 & 2.13 & 1.2 & 1.1 & 11 & & & & & 1.5 & & 1.5 & & 1.5 & 0.3 & & 0.2 & \\
\hline$H_{\mathrm{t}}(\mathrm{m})$ & \multicolumn{2}{|c|}{ Ta-max $(\mathrm{kN} / \mathrm{m})$} & \multicolumn{2}{|l|}{$l_{\min }$} & \multicolumn{2}{|c|}{$l_{\max }$} & \multicolumn{3}{|c|}{ Cost $(\$)$} & \multicolumn{9}{|c|}{ Saving with respect to equal lengths and spacings (\%) } \\
\hline 7 & \multicolumn{2}{|c|}{58.16621} & $1 \mathrm{~m}$ & & $10 n$ & $\mathrm{~m}$ & 234 & 729.7 & & 2.42 & & & & & & & & \\
\hline \multirow[t]{2}{*}{ Lengths } & $l_{1}$ & $l_{2}$ & $l_{3}$ & $l_{4}$ & $l_{5}$ & $l_{6}$ & & & Distances & $d_{1}$ & $d_{2}$ & & $d_{3}$ & $d_{4}$ & $d_{5}$ & $d_{6}$ & & $d_{7}$ \\
\hline & 9.99 & 3.77 & 2.49 & 1.55 & 1.22 & 1.12 & & & & 1.5 & 1. & .5 & 1.5 & 1.5 & 0.6 & 0.2 & & 0.2 \\
\hline$H_{\mathrm{t}}(\mathrm{m})$ & \multicolumn{2}{|c|}{ Ta-max $(\mathrm{kN} / \mathrm{m})$} & \multicolumn{2}{|l|}{$l_{\min }$} & \multicolumn{2}{|l|}{$l_{\max }$} & \multicolumn{3}{|c|}{ Cost (\$) } & \multicolumn{9}{|c|}{ Saving with respect to equal lengths and spacings (\%) } \\
\hline 9 & \multicolumn{2}{|c|}{59.78175} & $1 \mathrm{~m}$ & & $10 \mathrm{~m}$ & & 3197 & 6.72 & & 5.58 & & & & & & & & \\
\hline \multirow[t]{2}{*}{ Lengths } & $l_{1}$ & $l_{2}$ & $l_{3}$ & $l_{4}$ & $l_{5}$ & $l_{6}$ & $l_{7}$ & $l_{8}$ & Distances & $d_{1}$ & $d_{2}$ & $d_{3}$ & $d_{4}$ & $d_{5}$ & $d_{6}$ & $d_{7}$ & $d_{8}$ & $d_{9}$ \\
\hline & 10 & 9.96 & 6.3 & 3.74 & 2.65 & 1.73 & 1.58 & 1.32 & & 1.5 & 1.5 & 1.46 & 1.28 & 1.05 & 0.93 & 0.7 & 0.22 & 0.36 \\
\hline
\end{tabular}


Table $109 \mathrm{~m}$ Geogrid-reinforced Wall with $A_{\mathrm{m}}=0$ and $q_{\mathrm{s}}=10 \mathrm{kPa}$ with two different range for lengths

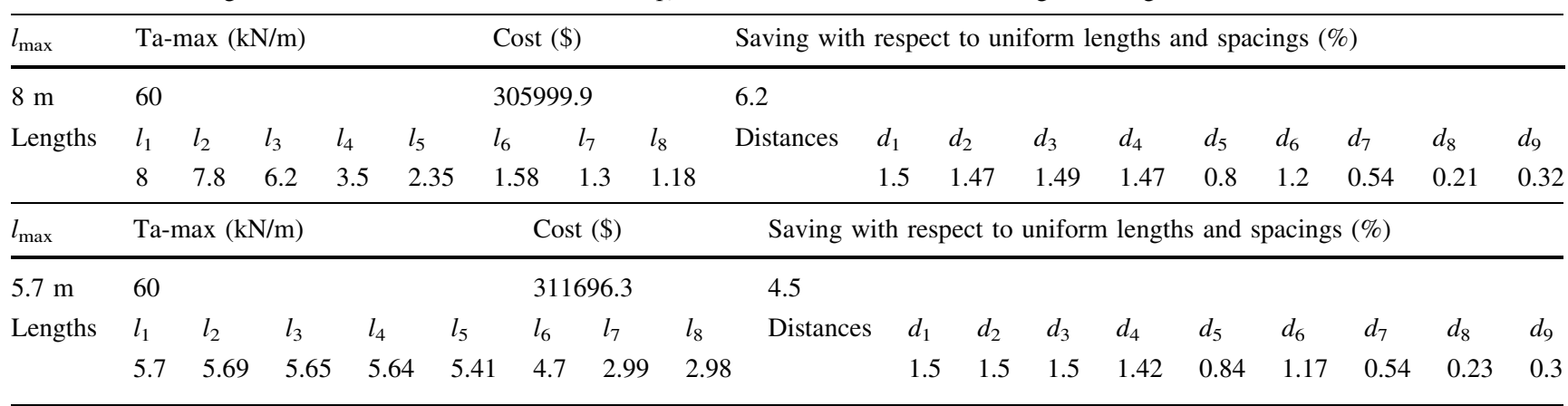

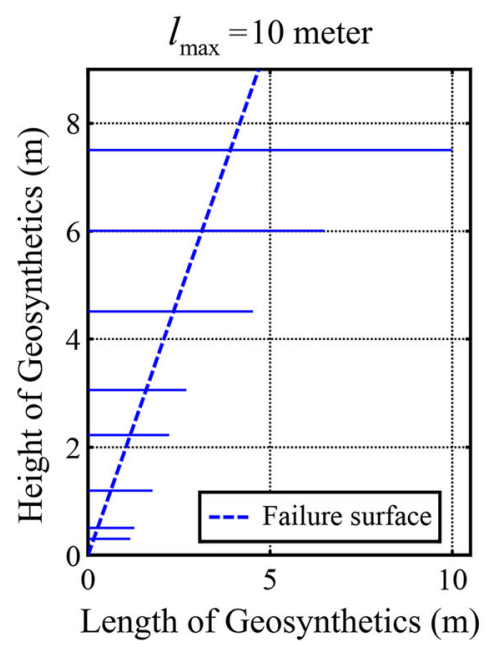

(a)

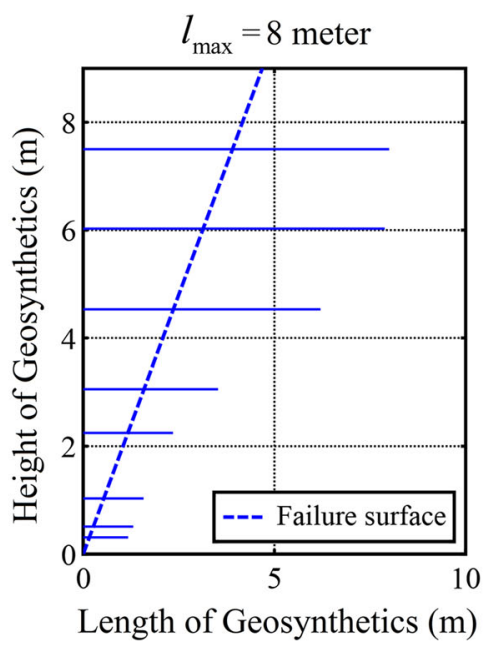

(b)

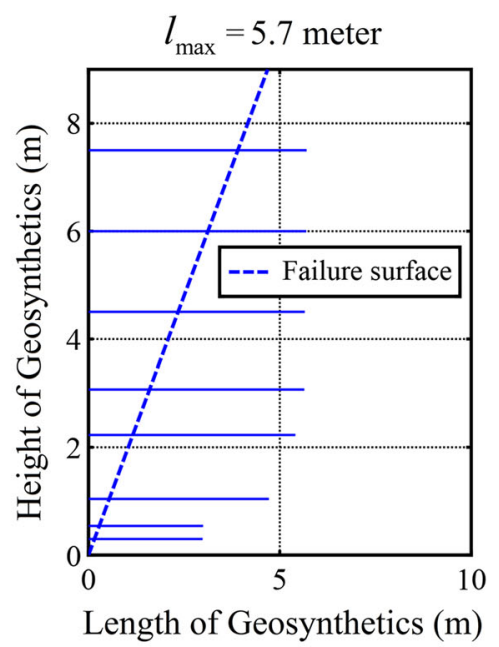

(c)

Fig. 4 Arrangement of geosynthetics for $9 \mathrm{~m}$ Geogrid-Wrap Wall with $A_{\mathrm{m}}=0$ and $q_{\mathrm{s}}=10 \mathrm{kPa}$ with three different range for lengths

The total saving in the presence of seismic loads was found to be lower (Tables 8, 9) compared to the other modes of analyses. This reduction in total saving can be related to the extent of seismic load considered in analysis. The inertial force was assumed to act over a zone of width equaling half of the wall height. This assumption indeed leads to a conservative design. The total saving for Geotextile-Wrapped Walls was found to be higher than that of Geogrid-reinforced Walls.

The range for the length of geosynthetic layers, for the results presented in all of the cases discussed in Tables 4, $5,6,7,8,9$, was $\left[l_{\min }, l_{\max }\right]=[1 \mathrm{~m}, 10 \mathrm{~m}]$. This range was selected to be consistent with a previous study done for uniform length and spacing values [1]. However, the authors would like to note that this range can be altered to increase the overlap of the geosynthetic layers which helps in enhancing the integrity of the reinforced zone. To compare the results with smaller ranges for lengths of geosynthetic and justify the arrangement of layers obtained by $I H S$ Algorithm, the optimization program is repeated for the $9 \mathrm{~m}$ Geogrid-reinforced wall with $A_{\mathrm{m}}=0$ and $q_{\mathrm{s}}=10 \mathrm{kPa}$. The lower bound is kept as 1 meter and the upper bound is changed to 9 and $5.7 \mathrm{~m}$ which is close to the optimum value of length for the case of equal length and spacing. The results are presented in Table 10.

It was obtained that, with decrease in $l_{\max }$, the amount of saving reduced. Figure 4 shows the arrangement of geothynsetics for $9 \mathrm{~m}$ Geogrid-Wrap Wall with $A_{\mathrm{m}}=0$ and $q_{\mathrm{s}}=10 \mathrm{kPa}$, and for three different $l_{\max }$. It is inferred that reducing the range over which the length of geosynthetic layers can vary, increases the length of geosynthetic for lower layers. Figure 4-c shows the arrangement for maximum length equal to 5.7 meter which was equal to the optimum length of geosynthetics for the case of same lengths and spacing [1]. Table 10 also indicates that, using variable lengths and spacing values, the total cost is higher compared to the case of equal lengths and spacing values [1] with same maximum length for both cases. It can be inferred from Fig. 4 that the overall trend for spacing and length is decreasing for lower layers. This trend is same for all heights and static and seismic analysis (see Tables 4, 5, $6,7,8,9)$. 
The range of spacing and lengths in this study are chosen to be equal to the previous study was performed by Manahiloh et al. [1]. This study mainly performed to examine the applicability of the mentioned method, however, it is desirable to decrease the spacing and increase the overlapping between layers that ensures the integrity of the reinforced zone.

\section{Conclusions}

In this study the principles involving different constrained optimization methods were highlighted. A novel improved harmony search algorithm (IHS) was developed and used to optimize the design of Geosynthetic-reinforced walls with non-uniform lengths and spacing values. Heuristic methods were employed to modify the traditional Harmony Search Algorithms and extend their capability to add a vectorcomposed of dependent variables - as a single variable in the process of defining the optimization problem. In each layer, the IHS algorithm was enabled to confine the strength of the geosynthetics to allowable values set using constraints. While strength requirements are met at each layer, the optimum tensile strength of the geosynthetics were set to correspond to those values that result in reduced overall cost of construction. In addition to the cost of geosynthetic itself, the big proportion of cost reduction came from the reduction of the volume of fill and the associated reduction in the length of reinforcements for lower layers.

The newly developed IHSA was applied to optimize the construction of geosynthetically reinforced earth walls of height 5, 7 and 9 meters. Various cases considered were: geotextile versus geogrid reinforcement; static $\left(A_{\mathrm{m}}=0\right)$ vs. dynamic $\left(A_{\mathrm{m}}=0.05\right)$ loading conditions; and the presence $\left(q_{\mathrm{s}}=10 \mathrm{kPa}\right)$ versus absence $\left(q_{\mathrm{s}}=0\right)$ of a surcharge load. The geometrical and loading values were selected to be consistent with a previous work with which relative observations were made. Cost savings were reported in comparison to the work done by Manahiloh et al. [1] using the "classic" $H S A$.

For geotextile-reinforced wall construction: for the case of no dynamic and no surcharge loads, the cost of construction of the 5,7 , and 9 meter walls showed a reduction of $2.67,4.62$, and $9.8 \%$ respectively; for the case where no dynamic load and $q_{\mathrm{s}}=10 \mathrm{kPa}$ were considered, the corresponding cost savings were found to be equal to $1.76,6.29$, and $10.45 \%$ respectively; and for the case where dynamic analysis is performed with $A_{\mathrm{m}}=0.05$ in the absence of surcharge, the cost reductions were $1.52,4.22$, and $8.54 \%$ respectively. In all cases, it was observed that the rate of cost saving increased with the height of the walls. For Geogridreinforced walls the cost savings was about $30 \%$ less than that of Geotextile-reinforced walls. In addition, the spacing between adjacent geosynthetic layers and the corresponding lengths were observed to decrease from top to bottom of the walls. The authors believe that the ideas implemented in this newly improved algorithm could be used towards optimizing the design of other geotechnical projects that involve variable parameters in their design.

\section{References}

1. Manahiloh KN, Motalleb Nejad M, Momeni MS (2015) Optimization of design parameters and cost of geosynthetic-reinforced earth walls using harmony search algorithm. Int $\mathbf{J}$ Geosynth Ground Eng 1:15

2. Pourbaba M, Talatahari S, Sheikholeslami R (2013) A chaotic imperialist competitive algorithm for optimum cost design of cantilever retaining walls. KSCE J Civ Eng 17(5):972-979

3. Yoo H, Kim H, Jeon H (2007) Evaluation of pullout and drainage properties of geosynthetic reinforcements in weathered granite backfill soils. Fibers Polym 8(6):635-641

4. Lawrence C (2014) High performance textiles and their applications. Woodhead Publishing, Boca Raton, pp 256-350

5. Zhang MX, Javadi AA, Lai YM, Sun J (2006) Analysis of geosynthetic reinforced soil structures with orthogonal anisotropy. Geotech Geol Eng 24:903-917

6. Koerner RM, Soong TY (2001) Geosynthetic reinforced segmental retaining walls. Geotext Geomembr 19(6):359-386

7. Kim JH, Geem ZW, Kim ES (2001) Parameter estimation of the nonlinear Muskingum model using harmony search. J Am Water Resour Assoc 37:1131-1138

8. Karahan H, Gurarslan G, Geem ZW (2013) Parameter estimation of the nonlinear muskingum flood-routing model using a hybrid harmony search algorithm. J Hydrol Eng 18(3):352-360

9. Paik K, Kim JH, Kim HS, Lee DR (2005) A conceptual rainfallrunoff model considering seasonal variation. Hydrol Process 19:3837-4385

10. Geem ZW (2006) Optimal cost design of water distribution networks using harmony search. Eng Optim 38:259-280

11. Ayvaz T (2007) Simultaneous determination of aquifer parameters and zone structures with fuzzy c-means clustering and metaheuristic harmony search algorithm. Adv Water Resour 30:2326-2338

12. Wang L, Pan Q, Tasgetiren M (2011) A hybrid harmony search algorithm for the blocking permutation flow shop scheduling problem. Comput Ind Eng 61:76-83

13. Degertekin SO (2008) Optimum design of steel frames using harmony search algorithm. Struct Multidiscip Optim 36:393-401

14. Zou D, Gao L, Wu J, Li S, Li Y (2010) A novel global harmony search algorithm for reliability problems. Comput Ind Eng 58(2):307-316

15. Lee KS, Geem ZW (2004) A new structural optimization method based on the harmony search algorithm. Compos Struct 82:781-798

16. Lee KS, Geem ZW, Lee SH, Bae KW (2005) The harmony search heuristic algorithm for discrete structural optimization. Eng Optim 37:663-684

17. Ceylan H, Haldenbilen S, Baskan O (2008) Transport energy modeling with metaheuristic harmony search algorithm, an application to Turkey. J Energy Policy 36:2527-2535

18. Kayhan AH, Korkmaz KA, Irfanoglu A (2011) Selecting and scaling real ground motion records using harmony search algorithm. Soil Dyn Earthq Eng 31:941-953 
19. Nazari T, Aghaie M, Zolfaghari A, Minuchehr A, Norouzi A (2013) WWER core pattern enhancement using adaptive improved harmony search. J Nucl Eng Design 254:23-32

20. Zarei O, Fesanghary M, Farshi B (2008) Optimization of multipass face-milling via harmony search algorithm. J Mater Process Technol 209:2386-2392

21. Nazari T, Aghaie M, Zolfaghari A, Minuchehr A, Shirani A (2013) Investigation of PWR core optimization using harmony search algorithms. J Ann Nucl Energy 57:1-15

22. Mahdavi M, Fesanghary M, Damangir E (2007) An improved harmony search algorithm for solving optimization problems. Appl Math Comput 188:1567-1579

23. Wu B, Qian C, Ni W, Fan S (2012) Hybrid harmony search and artificial bee colony algorithm for global optimization problems. Comput Math Appl 64(8):2621-2634

24. Shi WW, Han W, Si WC (2013) A hybrid genetic algorithm based on harmony search and its improving. Inf Manag Sci I 204:101-109

25. Wang L, Li LP (2013) An effective differential harmony search algorithm for the solving non-convex economic load dispatch problems. Electr Power Energy Syst 44(2013):832-843

26. Omran MGH, Mahdavi M (2008) Global-best harmony search. Appl Math Comput 198(2):643-656
27. Basudhar PK, Vashistha A, Deb K, Dey A (2008) Cost optimization of reinforced earth walls. Geotech Geol Eng 26:1-12

28. Elias V, Christopher BR, Berg RR (2001) Mechanically stabilized earth walls and reinforced soil slopes design \& construction guidelines. FHWA-NHI-00-043, p 394

29. Meyerhof GG (1953) The bearing capacity of foundation under eccentric and inclined loads. In: Third International Conference on Soil Mechanics and Foundation Engineering, Zurich

30. Das, M.B. (2007) Principles of foundation engineering. Sixth edn. Cengage learning

31. Terzaghi K (1943) Theoretical soil mechanics. Wiley, New York

32. AASHTO, Standard Specifications for Highway Bridges, with 2000 Interims (1996) American Association of State Highway and Transportation Officials, Fifteenth edn. Washington, D.C., USA

33. Yang X-S (2009) Harmony search as a metaheuristic algorithm. In: Music-inspired harmony search algorithm: theory and applications. Springer, Berlin

34. Geem ZW (2000) Optimal design of water distribution networks using harmony search, in Department of Civil and Environmental Engineering, Korea University 